\title{
THE EFFECT OF CHITOSAN COATING ON MAFENIDE ACETATE-LOADED LIPOSOME CHARACTERIZATION AND DELIVERY THROUGH BURNED RAT SKIN
}

\author{
BEHZAD SHARIF MAKHMAL ZADEH ${ }^{1,2 *}$, BAHAREH KHANDEH ZAMIN ${ }^{2}$ \\ ${ }^{1}$ Nanotechnology Research Center, Ahvaz Jundishapur University of Medical Sciences, Ahvaz, Iran. ${ }^{2}$ Department of Pharmaceutics, School \\ of Pharmacy, Ahvaz Jundishapur University of Medical Sciences, Ahvaz, Iran. Email: makhmalzadeh@yahoo.com
}

Received: 01 February 2019, Revised and Accepted: 25 May 2019

\section{ABSTRACT}

Objective: Mafenide acetate has appropriate antibacterial activity against Gram-positive bacteria isolated from the eschar surface. This drug has a high permeability through eschar which causes not only low concentration in the target place but also systemic toxicity. The aim of this study was localization of mafenide acetate into the eschar by chitosome.

Methods: In this study, liposomes are prepared with thin-layer hydration method and then covered by chitosan film. Based on full factorial design, different formulation was prepared and characterized and the selected formulation was applied on burned rat skin.

Results: Chitosan decreased membrane fluidity by interaction with phospholipid and cholesterol that induced lower drug loading efficiency and higher particle size of chitosomal formulation in comparison with liposomal formulations. Mucoadhesive and slow drug release property of chitosomes provided higher drug concentration into the eschar.

Conclusion: Impairment barrier property of eschar can be treated by the application of chitosomes. Chitosomes provided more drug concentration into the eschar and so are better vehicles for burn wound treatment in comparison with liposomes.

Keywords: Chitosome, Liposome, Burn wound treatment, Mafenide acetate.

(C) 2019 The Authors. Published by Innovare Academic Sciences Pvt Ltd. This is an open access article under the CC BY license (http://creativecommons. org/licenses/by/4. 0/) DOI: http://dx.doi.org/10.22159/ajpcr.2019.v12i7.32338

\section{INTRODUCTION}

Burns occupy a large body surface area and are a major cause of death due to subsequent infection. Disruption of the skin barriers, good accessibility of bacterial agents to nutrients, the inadequate vascular supply to the burned region, and a combination of systemic disturbance and immunosuppression are the major factors that make the skin susceptible to wound infection $[1,2]$.

A full-thickness burn is a damage to the skin caused by a variety of non- mechanical sources such as chemicals, electricity, heat, sunlight, and nuclear radiation. Burn wounds have three separate zones of concern: The zone of coagulation, the zone of stasis, which surrounds the zone of coagulation, and the zone of hyperemia, which surrounds the zone of stasis [3]. The coagulation zone is made up of dead, leathery tissue that forms the burn Escher, which initially forms 3-24 h post-burn [4]. Eschar is an open wound that lost all characteristics of normal skin and the absorption of water from adjacent tissue provides favorable conditions for microbial growth. Eschar is avascular and is frequently several mm distant from the patient's microvasculature. Furthermore, the diffusion of systemic antimicrobial agents may not achieve a therapeutic level. Topical antimicrobial therapy, however, remains the most important method for the control and management of wound infection. Topical application on eschar is one of the simplest methods for drug delivery. Choosing an antimicrobial agent is based on the spectrum and penetrating power it takes place within the eschar. One of the most effective antimicrobial compounds in the treatment of burn wound infection is mafenide acetate that has appropriate antibacterial activity against Gram-positive bacteria isolated from the Escher surface $[5,6]$. Mafenide acetate is an antimicrobial drug indicated as a primary agent in the treatment of burn wound infections. There were some reports about the toxic effects of mafenide acetate following topical administration. Mafenide acetate diffuses through devascularized areas and is rapidly absorbed from the burned surface; thus, it can result in systemic toxicity [6]. To promote drug localization, it is necessary to design a new drug delivery system for increasing drug trapping into the wound. Reduction in systemic absorption by topical liposomal administration has been reported [7]. Liposomes contain phospholipids and cholesterol and are useful vehicles for many hydrophilic and hydrophobic drugs due to their amphipathic identities [7]. Therefore, liposome was selected for mafenide acetate delivery through burned rat skin. However, traditional liposomes undergo aggregation, fusion, degradation, and drug leakage during storage [8]. The stability of liposomes can be improved by polymers such as chitosan [9]. Chitosan-coated liposome (chitosome) can enhance the stability, bioavailability [10,11], and drug controlled release [12]. Chitosan-coated liposomes are formed by ionic interaction between the positively charged chitosan and negatively charged phosphate on the surface of liposomes. Chitosan is also used to treat burn wound infection not only due to its antimicrobial properties but also by its wound healing effect and its ability to slow release drug delivery into the wound [13]. Therefore, in this study, we evaluated the chitosomes as mafenide acetate carrier for localization into the burned rat skin. The novelty of this study is using of lipid nanoparticles with mucoadhesive property for localization of mafenide acetate in burn wound that previously has not been reported.

\section{MATERIALS AND METHODS}

\section{Materials}

Mafenide acetate was a gift from Sina Daru (pharmaceutical company, Tehran, Iran). Chitosan (MW 750 kdKD, deacetylation degree $\geq 85 \%$ ) was purchased from Germany Fluka, phosphatidylcholine and cholesterol and chloroform were obtained from Merck (Germany). Cellulose acetate membrane 4-74-7 kDa cutoff was purchased by Toba Azma (Tehran, Iran). Acetone was purchased from Sabz Kooh Company (Tehran, Iran). All other materials were of the highest grade commercially available. Female adult Wistar rats (weighing 100-150 g) with the age of 10-12 weeks were purchased from animal's laboratory, Ahvaz Jundishapur University of Medical Sciences, Ahvaz, Iran. 


\section{Methods}

Animal experiment

Male Wistar rats with an average weight of $226 \pm 22.1 \mathrm{~g}$ were obtained from the Laboratory Animal Care and Breeding Center of Ahvaz Jundishapur University of Medical Sciences, Ahvaz, Iran, and kept for 7 days for acclimatization and given a standard diet and water. Water and food were removed $1 \mathrm{~h}$ before experimental trauma. Animals were treated following the principles for the care and use of laboratory animals and approval for the studies was given by the Ethical Committee of the Ahvaz Jundishapur University of Medical Sciences, Ahvaz, Iran. Approval for the studies was given by the Ethical Committee of the Ahvaz Jundishapur University of Medical Sciences (Approval No: N-803). The animals were anesthetized by intraperitoneal injection of ketamine/ xylazine, shaved, and burned dorsally by a smooth metal surface pre-heated to $100^{\circ} \mathrm{C}$ by electrical power for $15 \mathrm{~s}$ to produce a uniform, deep, second-degree burn measuring $4 \mathrm{~cm}$ in diameter. The animals were then killed with a lethal dose of ketamine; burned skin was removed with excess lipids being cleaned using acetone. These samples were used for the permeation experiment.

\section{Mafenide acetate assay method}

The amount of drug loading within liposomes and chitosomes and the release rate of the drug determined using ultraviolet (UV) spectroscopy at wavelengths of $267 \mathrm{~nm}$. The limit of quantification was $10 \mu \mathrm{g} / \mathrm{ml}$. Interday, intraday study, and recovery percentage revealed the accuracy and repeatability of this method.

\section{Liposome and chitosome preparation method}

Lipid phase consisting of $10 \mathrm{mg}$ phosphatidylcholine and cholesterol with different molar ratio was dissolved in $10 \mathrm{ml}$ organic solvent consisting of chloroform: methanol (3:1) ratio. In the following, the lipid solution was kept in a rotary evaporator (Buchi, Switzerland) during $3 \mathrm{~h}$ at $55^{\circ} \mathrm{C}$ and $50 \mathrm{rpm}$. Evaporation continued for one night at room temperature and vacuum condition until a thin lipid layer was observed. The dried thin film hydrated with phosphate buffer $(\mathrm{pH}=7)$ containing 1\% Mafenide acetate at 65 (above the gel-liquid crystal transition temperature of lipid) and well shaken for 3 minutes witha vortex. Finally, the latter suspension was kept in a sonicator bath (ELMA, Germany) for 1 and $5 \mathrm{~min}$ at 60 , to reduce particle size $[14,15]$.

For chitosome preparation, different amount of chitosan was dissolved under stirring in acetic acid (0.1\%) aqueous solution. Then mafenide acetate-loaded liposomes was slowly added to chitosan solution under stirring at $25^{\circ} \mathrm{C}$ for $1 \mathrm{hr}$. [15].

Liposome and chitosome characterization and stability evaluation For this purpose, particle size, drug entrapment efficiency (EE\%), and drug release profile have been evaluated.

\section{Particle size measurement}

Particle size was measured at $25^{\circ} \mathrm{C}$ by particle size analyzer. The mean droplet size of samples was determined by SCATTER SCOPE 1 QUIDIX (South Korea) based on photon correlation spectroscopy with a wide measurable size range (1-7000 $\mathrm{nm})$. Each sample was measured triplicate.

\section{Determination of mafenide acetate EE\%}

The amount of EE\% was determined by an ultrafiltration method to separate the free mafenide acetate. A defined amount defined amounts of mafenide acetate-loaded liposomes and chitosomes were added into centrifugal ultrafiltration tubes (Microcon MWCO 3000, Millipore Co, USA) and centrifuged at 30,000 for $30 \mathrm{~min}$ and $4^{\circ} \mathrm{C}$. Then, free mafenide acetate content was determined by UV-visible at $267 \mathrm{~nm}$, and then, EE\% was calculated as initially added drug minus the free drug (Equation 1). In addition, in the direct method, loaded mafenide acetate was determined after liposome and chitosome treatment with $0.5 \% \mathrm{w} / \mathrm{v}$ Triton X-100 as a detergent. The amount of loaded mafenide acetate was calculated by the following equation 2 [16].

$$
\begin{aligned}
& \mathrm{EE} \%=\frac{\text { total drug-diffused drug }}{\text { total drug }} \times 100 \\
& \mathrm{EE} \%=\frac{\text { loaded amount of mafenide acetate }}{\text { total amount of mafenide acetate }}
\end{aligned}
$$

Mafenide acetate release study from chitosomes and liposomes

Drug release profiles were obtained by static diffusion cells (Malek Teb, Iran) with thermoregulated water jacket and temperature maintained at $32-37^{\circ} \mathrm{C}$. A defined amount of each formulation centrifuged and precipitated was collected and suspended in water. About $5 \mathrm{ml}$ of suspension used as a donor phase and $30 \mathrm{ml}$ of buffer phosphate $(\mathrm{pH}=7)$ as a receptor phase. Samples were picked up in determined intervals over $48 \mathrm{~h}$ [17].

\section{Stability study}

For stability, chitosomes and liposomes stored at $30^{\circ} \mathrm{C}$ and relative humidity $65 \%$ for 3 months. A dramatic decrease in loading capacity or formation of cake in the suspension and also change in particle size and morphology is considered a sign of instability [18].

\section{Particle morphology}

Prepared nanoparticles were characterized for shape by atomic force microscopy (AFM). The samples were diluted with water and fixed on the mica surface.

\section{Evaluation of bilayer structure by Fourier transform infrared (FT- IR)}

In this section, liposomal and chitosomal samples with and without drug scanned in the range of $400-4000 \mathrm{~cm}^{-1}$ with a speed of $2 \mathrm{~cm} / \mathrm{s}$ with a $4 \mathrm{~cm}^{-1}$ resolution and examined the vibration band of the phospholipid hydrocarbon chain [19].

\section{RESULTS AND DISCUSSION}

Liposome and chitosomes composition based on full factorial design

This experiment was carried out according to full factorial design, includingfourvariablesontwolevels ( + : highleveland-:lowlevel). Sixteen formulations were prepared that their compositions summarized in Table 1.

\section{Mafenide acetate EE\%}

The determination of EE\% is inevitable for evaluating therapeutic efficiency. In this experiment, EE\% for each formulation of liposome and chitosome is presented in Table 2.

These results include the effect of variables on EE\% of liposomal and chitosomal formulations. The results indicated significant and indirect correlation between cholesterol percentage, aqueous phase volume and direct correlation of sonication time with EE\% in the liposomes, respectively. Therefore the highest liposomes loading percentage demonstrated by formulations 3 and 11 with the lower aqueous phase volume and higher sonication time. The loading percentage in chitosomes is lower than liposomes which show the effect of chitosan onthe reduction of loading capacity. The effect of cholesterol percentage and sonication time on drug loading into the chitosome is similar to liposomes. It seems that chitosan coated film decreased the affinity ofthe drug for loading into the vesicles. A similar result was reported for P neuropeptide loaded in chitosome [20].

\section{Liposomes and chitosomes particle size distribution}

The mean particle size of different liposomes and chitosomes is presented in Table 3.

The results show the higher particle size ofchitosomes in comparison to liposomes that caused by the chitosan-coated film. The sonication time demonstrated the significant and decreasing effect on the particle size of 
Table 1: Composition of liposome and chitosome formulations

\begin{tabular}{|c|c|c|c|c|c|c|c|}
\hline \multirow{2}{*}{$\begin{array}{l}\text { Formulation } \\
\text { number }\end{array}$} & \multirow{2}{*}{$\begin{array}{l}\text { State in full } \\
\text { factorial design }\end{array}$} & \multicolumn{2}{|c|}{ Lipid percentage } & \multirow{2}{*}{$\begin{array}{l}\text { Chitosan } \\
\text { percentage }\end{array}$} & \multirow{2}{*}{$\begin{array}{l}\text { Span } 20 \\
\text { percentage }\end{array}$} & \multirow{2}{*}{$\begin{array}{l}\text { Aqueous } \\
\text { phase (cc) }\end{array}$} & \multirow{2}{*}{$\begin{array}{l}\text { Sonication } \\
\text { time (min) }\end{array}$} \\
\hline & & $\begin{array}{l}\text { Cholesterol } \\
\text { percentage }\end{array}$ & $\begin{array}{l}\text { Lecithin } \\
\text { percentage }\end{array}$ & & & & \\
\hline 2 & -+++ & 1 & 1 & 1 & 1 & 10 & 1 \\
\hline 3 & +-++ & 1 & 1 & 1 & 1 & 5 & 5 \\
\hline 4 & ++-+ & 1 & 1 & 0.4 & 1 & 10 & 5 \\
\hline 5 & +++- & 1 & 3 & 1 & 1 & 10 & 5 \\
\hline 6 & --++ & 1 & 1 & 1 & 1 & 5 & 1 \\
\hline 7 & ++-- & 1 & 3 & 0.4 & 1 & 10 & 5 \\
\hline 8 & +-+- & 1 & 3 & 0.4 & 1 & 5 & 5 \\
\hline 9 & -+-+ & 1 & 1 & 0.4 & 1 & 10 & 1 \\
\hline 10 & -++- & 1 & 3 & 1 & 1 & 10 & 1 \\
\hline 11 & +--+ & 1 & 1 & 0.4 & 1 & 5 & 5 \\
\hline 12 & +--- & 1 & 3 & 0.4 & 1 & 5 & 5 \\
\hline 13 & -+-- & 1 & 3 & 0.4 & 1 & 10 & 1 \\
\hline 14 & --+- & 1 & 3 & 1 & 1 & 5 & 1 \\
\hline 16 & ---- & 1 & 3 & 0.4 & 1 & 5 & 1 \\
\hline
\end{tabular}

+: high level of independent variable, -: low level of independent variable

Table 2: Entrapment efficiency percentage of liposome and chitosome formulations mean \pm standard deviation $(n=5)$

\begin{tabular}{|c|c|c|c|}
\hline \multirow{2}{*}{$\begin{array}{l}\text { Formulation } \\
\text { number }\end{array}$} & \multirow{2}{*}{$\begin{array}{l}\text { State in full } \\
\text { factorial design }\end{array}$} & \multicolumn{2}{|l|}{ EE\% } \\
\hline & & $\begin{array}{l}\text { Liposome } \\
\text { formulations }\end{array}$ & $\begin{array}{l}\text { Chitosome } \\
\text { formulations }\end{array}$ \\
\hline 1 & ++++ & $75.7 \pm 2.9$ & $36.5 \pm 3.3$ \\
\hline 2 & -+++ & $60.6 \pm 2.7$ & $30.6 \pm 3.2$ \\
\hline 3 & +-++ & $83.6 \pm 2.55$ & $42.4 \pm 4.3$ \\
\hline 4 & ++-+ & $75.7 \pm 2.94$ & $48.1 \pm 2.3$ \\
\hline 5 & +++- & $60.6 \pm 3.2$ & $25.9 \pm 2.6$ \\
\hline 6 & --++ & $73.9 \pm 4.4$ & $32.90 \pm 2.6$ \\
\hline 7 & ++-- & $60.6 \pm 3.2$ & $35.5 \pm 2.4$ \\
\hline 8 & +-+- & $67.4 \pm 2.5$ & $28.7 \pm 2.4$ \\
\hline 9 & -+-+ & $60.6 \pm 2.7$ & $43.7 \pm 4.2$ \\
\hline 10 & -++- & $57 \pm 2.6$ & $23.3 \pm 1.8$ \\
\hline 11 & +--+ & $83.6 \pm 2.55$ & $51.5 \pm 9.1$ \\
\hline 12 & +--- & $67.4 \pm 2.5$ & $48.3 \pm 3.2$ \\
\hline 13 & -+-- & $57 \pm 2.6$ & $30.3 \pm 2.2$ \\
\hline 14 & --+- & $60.2 \pm 2.4$ & $23.7 \pm 2.8$ \\
\hline 15 & ---+ & $73.9 \pm 4.4$ & $49.8 \pm 4.5$ \\
\hline 16 & --- & $60.3 \pm 2.5$ & $43.7 \pm 3.9$ \\
\hline
\end{tabular}

EE: Entrapment efficiency, +: high level of independent variable, -: low level of independent variable

Table 3: Liposomes and chitosomes mean particle size, mean \pm standard deviation $(n=5)$

\begin{tabular}{llll}
\hline $\begin{array}{l}\text { Formulation } \\
\text { number }\end{array}$ & $\begin{array}{l}\text { Full } \\
\text { factorial } \\
\text { state }\end{array}$ & $\begin{array}{l}\text { Liposome } \\
\text { particle } \\
\text { size (nm) }\end{array}$ & $\begin{array}{l}\text { Chitosome } \\
\text { particle } \\
\text { size (nm) }\end{array}$ \\
\hline 1 & ++++ & $101.8 \pm 40.2$ & $276 \pm 50.7$ \\
2 & -+++ & $233.7 \pm 34.42$ & $400 \pm 77.1$ \\
3 & +-++ & $40.2 \pm 12.1$ & $164.6 \pm 36.5$ \\
4 & ++-+ & $101.8 \pm 40.1$ & $169.3 \pm 21.8$ \\
5 & +++- & $42.9 \pm 28.5$ & $443.6 \pm 45$ \\
6 & --++ & $51.9 \pm 6.5$ & $193.3 \pm 18.6$ \\
7 & ++-- & $42.9 \pm 28.5$ & $360.3 \pm 33.2$ \\
8 & +-+- & $20.1 \pm 4.7$ & $285.3 \pm 28.5$ \\
9 & -+-+ & $233.6 \pm 34.4$ & $283.3 \pm 20.5$ \\
10 & -++- & $62.3 \pm 9.3$ & $765 \pm 37.6$ \\
11 & +--+ & $43.8 \pm 14.85$ & $133.3 \pm 13.1$ \\
12 & +--- & $20.1 \pm 8.66$ & $178.6 \pm 16.9$ \\
13 & -+-- & $62.3 \pm 9.3$ & $244.6 \pm 33.5$ \\
14 & --+- & $103.5 \pm 11.3$ & $304 \pm 39.2$ \\
15 & ---+ & $51.96 \pm 6.5$ & $174.3 \pm 14.7$ \\
16 & --- & $103.5 \pm 29.7$ & $194 \pm 15.1$ \\
\hline+ high level of independent variable, -: low level of independent variable
\end{tabular}

liposomes and chitosomes. Direct and significant correlation between chitosan percentage and particle size indicated in this research.

\section{Liposome and chitosome release studies}

To evaluate the influence of independent variables and chitosan film on drug release pattern, once we studied the amounts of drug release as a response and by plotting drug release curve against time. Fig. 1 presents information about mafenide acetate release through liposomes and chitosomes. Both liposomal and chitosomal formulations showed slow release profiles in this manner that after $48 \mathrm{~h}, 40 \%-50 \%$ of drug loaded released from chitosomes and 40\%-65\% from liposomes. The retardant effect of chitosan film on the release of harmine through liposome has been reported [21,22].

\section{FT-IR RESULTS}

FT-IR is a non-perturbing technique to evaluate of interaction between phospholipid and chitosan by analyzing the frequency and bandwidth of vibrational modes belong to functional groups. Fig. 2 shows the FT-IR spectra of the liposome with the drug (A), liposome without the drug (B), chitosome with the drug (C), and chitosome without the drug (D). Three main vibrational bands found in the chitosome and liposome spectra. A band was found at $3300-3500 \mathrm{~cm}^{-1}$ that is attributed to the $\mathrm{CH} 2$ stretching vibrational of phospholipid acyl chains. This band frequency decreased for chitosome that implies a decrease in membrane fluidity [19]. It seems that interaction between chitosan and phospholipid stabilized membrane in the gel phase. Another band has appeared at $1600-1800 \mathrm{~cm}^{-1}$ accorded to $\mathrm{C}=0$ stretching in the head group of the phospholipid [22,23]. This band slightly shifted in the presence of chitosan to lower frequency and higher intensity which is another reason for gel phase formation and membrane stability. The decrease in frequency may indicate new hydrogen bonding formation in the membrane. The third band that is appeared at $700-900 \mathrm{~cm}^{-1}$ is attributed to a steroid ring stretching in the cholesterol that used as the lipid phase. This band shifted to a lower frequency and higher intensity in the chitosome indicates an interaction between chitosan and cholesterol the same as phospholipid. Therefore, the interaction between chitosan and phospholipid and cholesterol as the lipid phase increased membrane stability that influenced on drug release and liposome stability.

\section{Morphology study}

AFM picture of chitosomal formulation no. 6 is shown in Fig. 3. illustrates forming liposome and chitosome with uniform shape and size.

Liposome and chitosome stability

Several physicochemical parameters are investigated as major reasons for liposome instability. Oxidation and hydrolytic reaction are the 


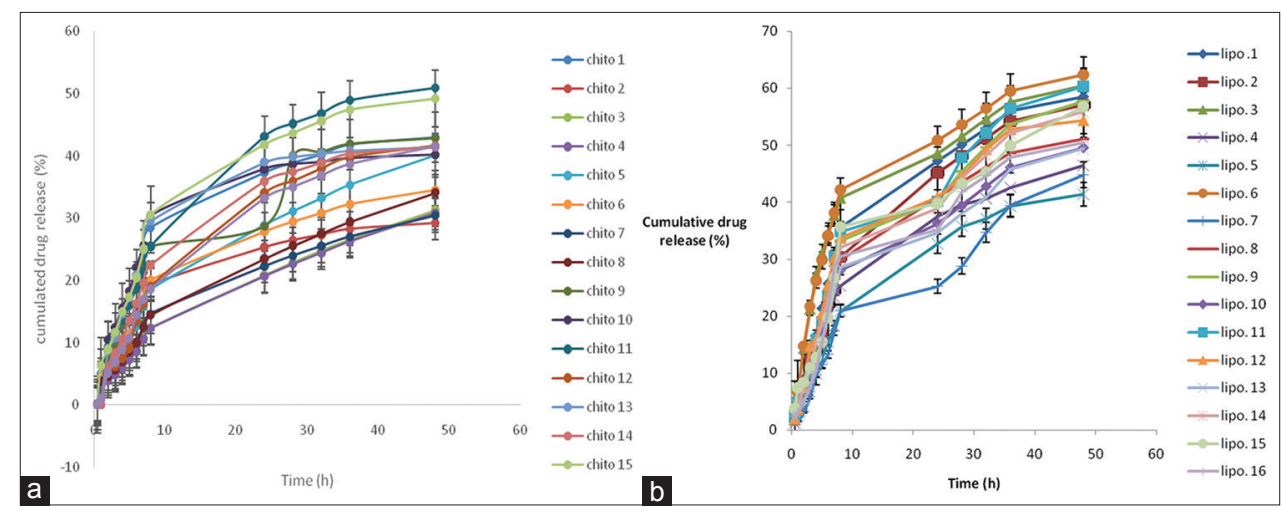

Fig. 1: Drug released from chitosomes (a) and liposomes (b)
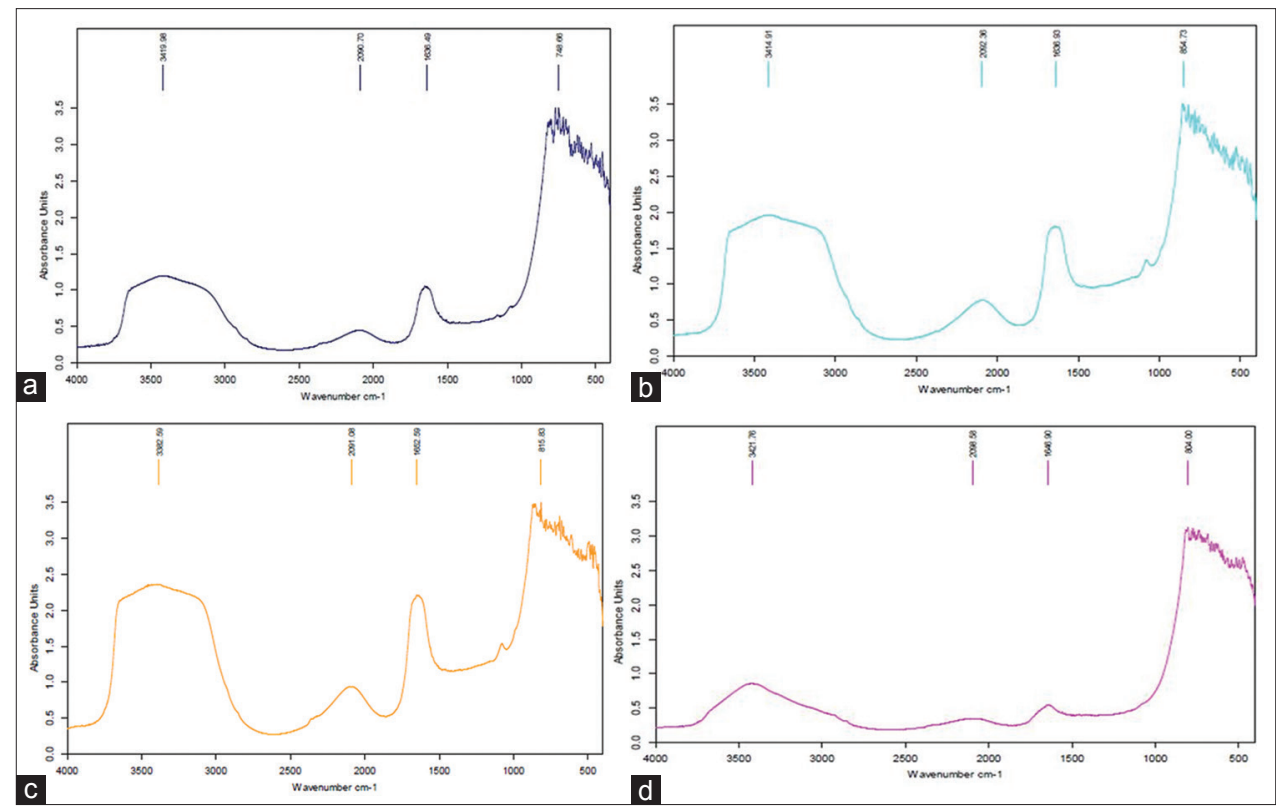

Fig. 2: FT-IR spectra of different formulations (liposome with drug (a), liposome without drug (b), chitosome with drug (c), chitosome without drug (d)

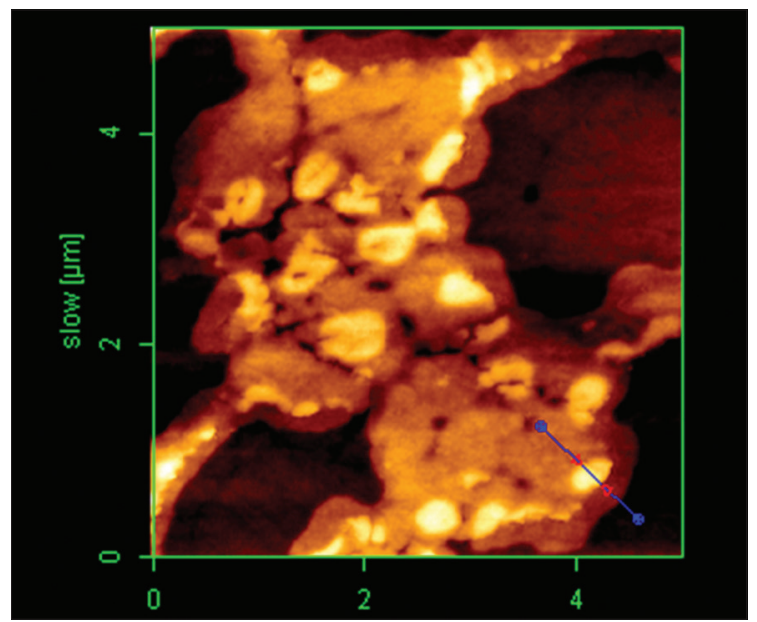

Fig. 3: AFM picture of chitosome formulation 5

main reasons for chemical instability, as they occur in phospholipid unsaturated chains. Storing at low temperatures and light preservation can avoid such reactions. $\mathrm{pH}$ adjustment, temperature, ionic interaction and application of cholesterol in bilayer structure can successfully cause liposome stability. In this study, chitosomes and liposomes were stored at $30^{\circ}$ and relative humidity $65 \%$ for 3 months. In these condition, their appearance was not changed. The particle size of the liposomes was increased and the loading capacity was reduced by $10 \%$ but for chitosomes no change in particle size and loading occurred.

\section{Skin permeation study}

The permeation studies through full-thickness rat skin were done after applying 1\% mafenide acetate-loaded in liposome no. 5 with the highest release rate and chitosome no. 6 with the high concentration of chitosan and their permeability parameters calculated in comparison with an aqueous solution of mafenide acetate. The results are shown in Table 4. Cumulative rivastigmine mafenide acetate permeated in $48 \mathrm{~h}\left(\mathrm{Q}_{48}\right)$, steady-state fluxes (Jss), diffusion coefficient (D), and the common time $\left(\mathrm{T}_{\mathrm{lag}}\right)$ were calculated and used for evaluation of the effect of selected liposomal and chitosomal formulations on mafenide acetate permeation through rat skin. Liposome and chitosome decreased significantly $(p<0.05) Q_{48}$ and Jss values through rat skin in comparison with control. Chitosome increased mafenide acetate localization into the burned skin more than liposome. It seems that mucoadhesive property of chitosan and slow drug release through chitosome increased drug depot in the skin. On the other hand, chitosome decreased all permeation parameters except $\mathrm{T}_{\mathrm{lag}}$ that means mafenide acetate partitioning into the skin and diffusion through the burned skin was decreased by chitosomes. This effect is due to the electrostatic 
Table 4: Mafenide acetate-loaded optimized liposome permeability parameter through rat skin against control mean \pm standard deviation $(n=5)$

\begin{tabular}{|c|c|c|c|c|}
\hline \multirow[t]{2}{*}{ Batch type } & \multicolumn{4}{|c|}{ Permeability parameters } \\
\hline & $\mathbf{Q}_{48}$ & Jss (mg/cm².h) & $\mathrm{D}\left(\mathrm{cm}^{2} / \mathrm{h}\right)$ & $T_{\text {lag }}(h)$ \\
\hline Aqueous control & $81.3 \pm 10.3$ & $3.12 \pm 0.34$ & $9 \times 10^{-5} \pm 1.1 \times 10^{-5}$ & $1.58 \pm 0.19$ \\
\hline Liposome & $20.5 \pm 2.4$ & $0.71 \pm 0.6$ & $3.8 \times 10^{-5} \pm 3.6 \times 10^{-6}$ & $3.89 \pm 0.41$ \\
\hline Chitosome & $10.3 \pm 1.2$ & $0.33 \pm 0.02$ & $2.6 \times 10^{-5} \pm 3.2 \times 10^{-6}$ & $4.45 \pm 0.38$ \\
\hline
\end{tabular}

interaction between the positive charge of chitosan and the negative charge of skin that helps to drug localization into the skin. Therefore, a chitosome can improve skin barrier that is damaged through burning. Chitosomes may cover the burned skin and increase skin hydration and recovery some barrier properly.

\section{DISCUSSION}

To develop optimal use of mafenide acetate in burn wound treatment, an animal burned tissue model has been utilized. Drug localization in the burn wound reduces systemic drug toxicity and increases the antimicrobial effectiveness. Mafenide acetate absorption from a 5\% aqueous solution into excised human and rat burned skin was studied using C14-labeled mafenide acetate [24]. They reported that final concentration of mafenide acetate in the human and rat burned tissues was similar and concluded that rat skin is useful mode due to similarity to human tissue. The peak of mafenide acetate concentration in burned human and rat skin was reached at $4 \mathrm{~h}$ after application. Based on this report, the concentrations of mafenide acetate in burned human and rat skin were 1.25 and $1 / 100 \mathrm{mg}$ tissue, respectively. In another study that $5 \%$ mafenide acetate cream was applied on burned human and rat skin, the peak concentration in both tissues was $0.5 / 100 \mathrm{mg}$ tissue that was reached at $2 \mathrm{~h}$ [25]. The contrast between two mentioned studies it is concluded that mafenide acetate penetrates the total thickness of the burn rapidly and reached the sub-eschar within $30 \mathrm{~min}$. The rate and amount of mafenide acetate penetration through the eschar is dependent on drug carrier. In the present study, we loaded mafenide acetate into chitosome and the results showed that the amounts of mafenide acetate permeated through the burned rat skin after application of aqueous solution, liposome, and chitosome containing $5 \%$ mafenide acetate were $0.65,0.21$, and $0.092 / 100 \mathrm{mg}$ of tissue. The contrast between our results and the previous studies shows that chitosome and liposomes decreased mafenide acetate permeation through burned skin that provides more drug concentration in burned tissue compared with aqueous solution and cream. Based on these observations, it is defined that reapplication frequency of chitosome and liposome is less than cream and aqueous solution. Mafenide acetate has painful nature 24 when applied on the wound. Therefore, using chitosome as drug carrier can reduce the drawbacks to use mafenide acetate.

\section{CONCLUSION}

Liposomes that were prepared bythe thin layer hydration method and coated by chitosan indicated different physicochemical properties against liposomes. Liposome with lower particle size demonstrated higher drug loading that sonication time indicated direct and significant effect on drug loading. Based on particle size analyzing it seems that with higher sonication time large uni-lamellar and large multi-lamellar liposomes change into small uni-lamellar liposomes. This change increased partitioning of mafenide acetate as a hydrophilic molecule into the aqueous core. Chitosomes stabilized membrane with interaction by phospholipid acyl chains and head group and produced vesicles with drug slow release rate. Mucoadhesive and drug slow release properties of chitosomes caused drug localization into the burned rat skin more than liposome. Impaired burned skin barrier is the important reason for low drug concentration in the Escher that can be dissolved by the application of chitosome. Chitosomes provided higher drug concentration in burn wound and so chitosome is better vehicle for burn wound treatment in comparison with liposome.

\section{ACKNOWLEDGMENT}

This paper is issued from the Pharm D thesis (Bahareh Khandeh zamin) and financial support was provided by Ahvaz Jundishapur University of Medical Sciences.

\section{AUTHORS' CONTRIBUTIONS}

The first author designed and conducted the experiment and drafted the manuscript. The second author carried out the experiment under the supervision of the first author.

\section{CONFLICTS OF INTEREST}

The authors declare no conflicts of interest.

\section{REFERENCES}

1. Dai T, Huang YY, Sharma SK, Hashmi JT, Kurup DB, Hamblin MR, etal. Topical antimicrobials for burn wound infections. Recent Pat Antiinfect Drug Discov 2010;5:124-51.

2. Moghimi HR, Makhmalzadeh BS, Manafi A. Enhancement effect of terpenes on silver sulphadiazine permeation through third-degree burn eschar. Burns 2009;35:1165-70.

3. Arturson G. Pathophysiology of the burn wound and pharmacological treatment. The Rudi Hermans lecture, 1995. Burns 1996;22:255-74.

4. Williams WG. In: Herendon DN, editor. Pathophysiology of Burn Wound. London: Total Burn Care. Susnders; 2002. p. 514-22.

5. Monafo WW, West MA. Current treatment recommendations for topical burn therapy. Drugs 1990;40:364-73.

6. Stefanides MM, Copeland CE, Kominos SD, Yee RB. In vitro penetration of topical antiseptics through eschar of burn patients. Ann Surg 1976;183:358-64.

7. Salem HF, Tamam SM, Lotayef SM. Biodegradable liposome for acyclovir-gold nanoparticles as an efficient carrier for enhanced topical delivery. Int J Pharm Pharm Sci 2017;9:60-4.

8. Hao J, Guo B, Yu S, Zhang W, Zhang D, Wang J, et al. Encapsulation of the flavonoid qurecetin with chitosan coated nano-liposomes. Food Sci Tech 2017;85:37-44.

9. Zhou F, Xu T, Zhao Y, Song H, Zhang L, Wu X, et al. Chitosan-coated liposomes as delivery systems for improving the stability and oral bioavailability of acteoside. Food Hydrocoll 2018;83:17-24

10. Peng S, Zou L, Liu W, Li Z, Liu W, Hu X, et al. Hybrid liposomes composed of amphiphilic chitosan and phospholipid: Preparation, stability and bioavailability as a carrier for curcumin. Carbohydr Polym 2017;156:322-32.

11. Liu W, Liu J, Liu W, Li T, Liu C. Improved physical and in vitro digestion stability of a polyelectrolyte delivery system based on layer-by-layer self-assembly alginate-chitosan-coated nanoliposomes. J Agric Food Chem 2013;61:4133-44.

12. Lee CM, Kim DW, Lee KY. Effect of chitosan coating for liposomes as an oral carrier. J Exp Biomed Sci 2011;17:211-6.

13. Sadhasivam L, Dey N, Fraocis AP, Devasena T. Transdermal patches of chitosan nanoparticles for insulin delivery. Int J Pharm Pharm Sci 2015;7:84-8

14. Zadeh BS, Azh Z, Azarpanah Z. Preparation and evaluation of mafenide acetate liposomal formulation as eschar delivery system. Int J Drug Dev Res 2011;3:156-64.

15. Takeuchi H, Matsui Y, Sugihara H, Yamamoto H, Kawashima Y. Effectiveness of submicron-sized, chitosan-coated liposomes in oral administration of peptide drugs. Int J Pharm 2005;303:160-70.

16. Karami MA, Zadeh BS, Kouchek M, Moghimipour E. Superoxide dismutase-loaded solid lipid nanoparticles prepared by cold homogenization method: Characterization and permeation through burned rat skin. Jundishapur J Nat Pharm Prod 2016;11:e33968.

17. Souto EB, Wissing SA, Barbosa CM, Müller RH. Development of 
a controlled release formulation based on SLN and NLC for topical clotrimazole delivery. Int J Pharm 2004;278:71-7.

18. Bhatia A, Kumar R, Katare OP. Tamoxifen in topical liposomes: Development, characterization and in-vitro evaluation. J Pharm Pharm Sci 2004; 7:252-9.

19. Mady MM, Darwish MM, Khalil S, Khalil WM. Biophysical studies on chitosan-coated liposomes. Eur Biophys J 2009;38:1127-33.

20. Mengoni T, Adrian M, Pereira S, Santos-Carballal B, Kaiser M, Goycoolea FM, et al. A chitosan-based liposome formulation enhances the in vitro wound healing efficacy of substance $\mathrm{P}$ neuropeptide. Pharmaceutics 2017;9:1-7.

21. Mady MM, Darwish MM. Effect of chitosan on the characteristics of
DPPC liposomes. J Adv Res 2010;1:187-91.

22. Chen WL, Yuan ZQ, Liu Y, Yang SD, Zhang CG, Li JZ, et al. Liposomes coated with N-trimethyl chitosan to improve the absorption of harmine in vivo and in vitro. Int J Nanomedicine 2016;11:325-36.

23. Nzai JM, Proctor A. Determination of phospholipids in vegetable oil by FT-IR. J Am Oil Chem Soc 1998;75:1281-9.

24. Harrison HN, Bales HW, Jacoby F. The absorption into burned skin of sulfamylon acetate from 5 per cent aqueous solution. J Trauma 1972;12:994-8.

25. Harrison HN, Blackmore WP, Bales HW, Reeder W. The absorption of C 14-labeled sulfamylon acetate through burned skin. I. Experimental methods and initial observations. J Trauma 1972;12:986-93. 